\title{
Avances en Neurociencias:
}

Neuropéptidos Investigación básica y clínica

\section{Rafael Coveñas - Luis Aguilar}

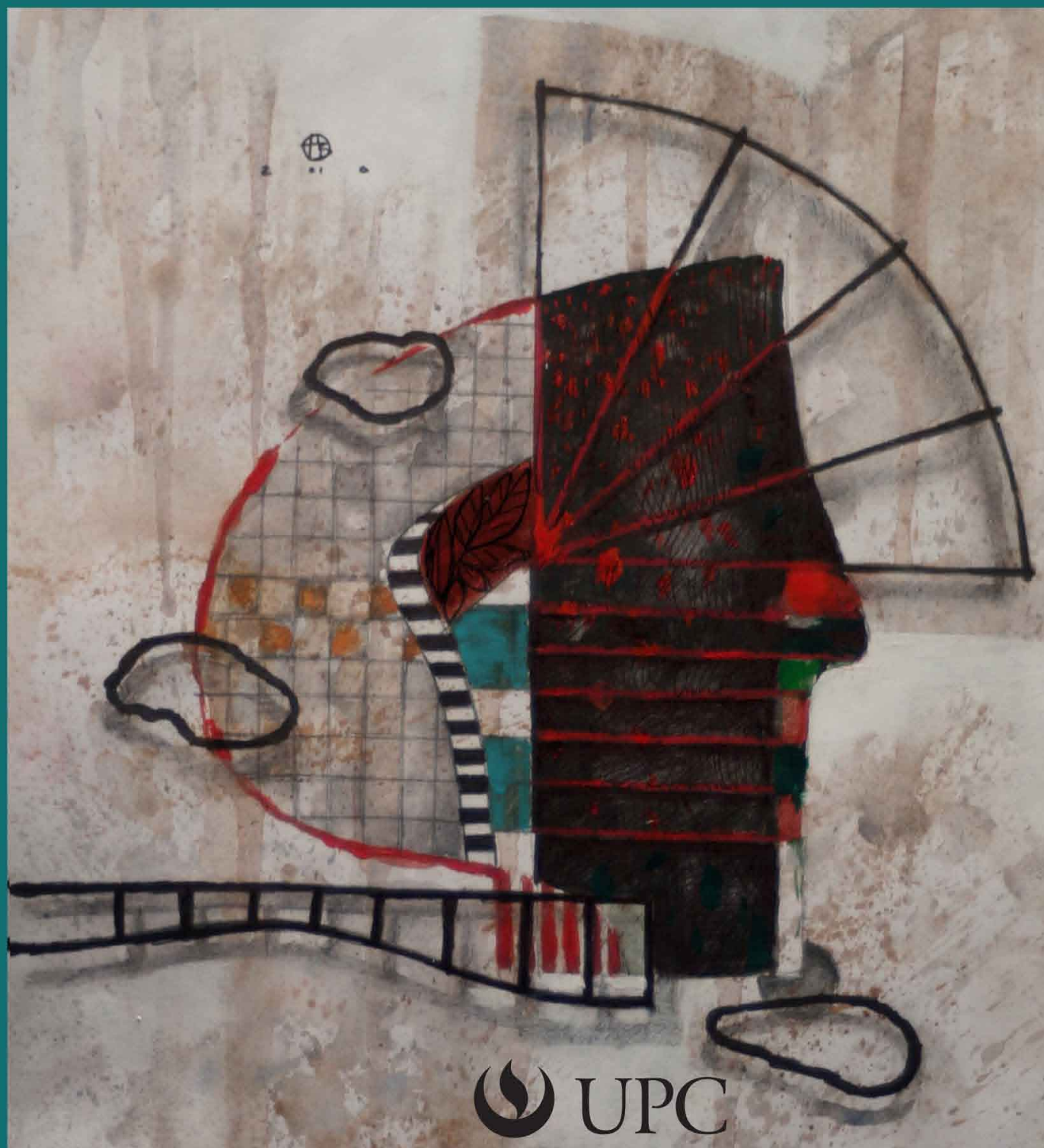


Avances en Neurociencias: Neuropéptidos Investigación básica y clínica

Rafael Coveñas Luis Aguilar 


\section{Avances en Neurociencias:}

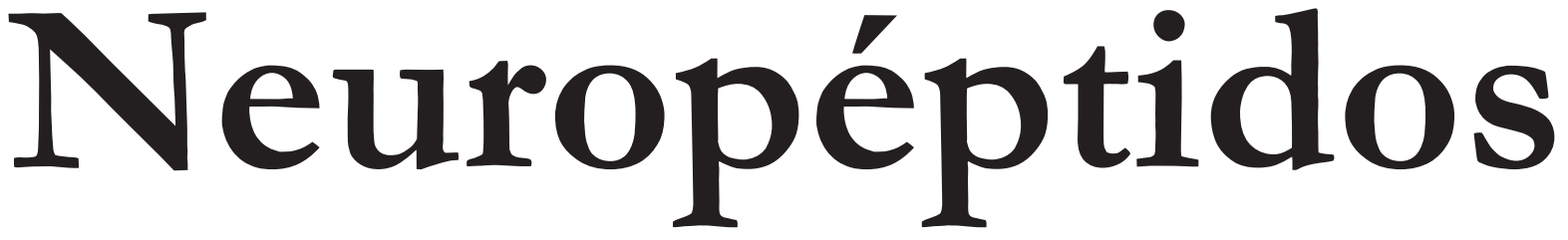

Investigación básica y clínica

Rafael Coveñas Rodríguez PhD.

Instituto de Neurociencias de Castilla y León (INCYL)

Laboratorio de Neuroanatomía de los Sistemas Peptidérgicos

Salamanca, España

Luis Ángel Aguilar Mendoza PhD.

Facultad de Ciencias de la Salud

Escuela de Medicina

Universidad Peruana de Ciencias Aplicadas (UPC)

Lima, Perú 
Autores: Rafael Coveñas y Luis Aguilar

(C) Universidad Peruana de Ciencias Aplicadas (UPC)

Primera publicación: mayo de 2010

Impreso en el Perú - Printed in Peru

Cubierta:

Edición médica:

Hernán Sosa

Corrección de estilo:

Revistas Especializadas Peruanas S. A. C.

Diseño de cubierta:

Dr. Jorge Candiotti

Diagramación:

Germán Ruiz Ch.

Ilustraciones:

Revistas Especializadas Peruanas S. A. C.

Revistas Especializadas Peruanas S. A. C.

Editor del proyecto editorial

(C) Universidad Peruana de Ciencias Aplicadas S. A. C.

Av. Alonso de Molina 1611, Lima 33, Perú. Telef. 313-3333

http://www.upc.edu.pe

Primera edición: año 2010

Tiraje: 1000 ejemplares

Este libro se terminó de imprimir en el mes de mayo de 2010, en los talleres gráficos de Revistas Especializadas Peruanas S. A. C., ubicados en Emilio Althaus 355, Lince. Lima, Perú.

Tel. 422-0888.

\section{Universidad Peruana de Ciencias Aplicadas (UPC) Centro de Información}

Coveñas, Rafael; y Aguilar, Luis. Avances en Neurociencias: Neuropéptidos. Investigación básica y clínica.

Lima: Universidad Peruana de Ciencias Aplicadas (UPC), 2010

ISBN 978-612-4041-45-7

\section{NEUROPÉPTIDOS, SISTEMA NERVIOSO, ENFERMEDADES, TRASTORNOS MENTALES, INVESTIGACIÓN BIOMÉDICA}

612.8042 COVE

Registro de Proyecto Editorial en la Biblioteca Nacional del Perú № 31501401000366 Hecho el depósito legal en la Biblioteca Nacional del Perú N²010-05417

Todos los derechos reservados. Esta publicación no puede ser reproducida, ni en todo ni en parte, ni registrada en o transmitida por un sistema de recuperación de información, en ninguna forma ni por ningún medio, sea mecánico, fotoquímico, electrónico, magnético, electroóptico, por fotocopia o cualquier otro, sin el permiso previo, por escrito, de la editorial.

El contenido de este libro es responsabilidad de los autores y no refleja necesariamente la opinión de los editores.

\section{NOTA}

La medicina es un área en constante evolución. Aunque deben seguirse unas precauciones de seguridad estándar, a medida que aumenten nuestros conocimientos gracias a la investigación básica y clínica habrá que introducir cambios en los tratamientos y en los fármacos. En consecuencia, se recomienda a los lectores que analicen los últimos datos aportados por los fabricantes sobre cada fármaco para comprobar la dosis recomendada, la vía y duración de la administración y las contraindicaciones. Es responsabilidad ineludible del médico determinar la dosis y el tratamiento más indicado para cada paciente en función de su experiencia y del conocimiento de cada caso concreto. Ni los editores ni los directores asumen responsabilidad alguna por los daños que pudieran generarse a personas o propiedades como consecuencia del contenido de esta obra. 
Sueño 135

Técnica mixta sobre papel

$0,20 \times 0,25 m$

2010

La Universidad Peruana de Ciencias Aplicadas (UPC) agradece a Hernán Sosa la cesión de su cuadro reproducido en la cubierta. 
A mi esposa Mercedes y mis hijos Rafael y María:

Rafael

A mi esposa Irma, mis padres, hermanos $y$ familia:

Luis 


\section{Contenido}

I PRESENTACIÓN ....................................................... 11

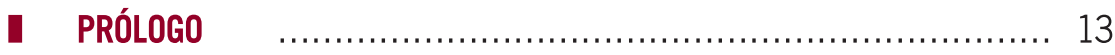

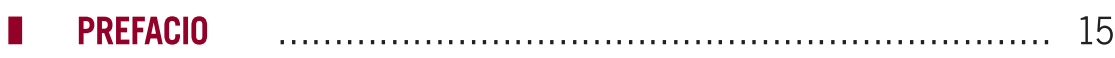

I PARTE I. INTRODUCCIÓN

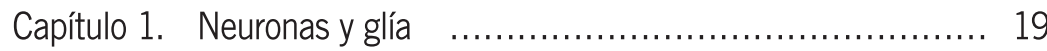

Capítulo 2. Sinapsis ................................................. 25

Capítulo 3. Regeneración y muerte celular ........................... 35

Capítulo 4. Meninges. Líquido cefalorraquídeo. Organización general del sistema nervioso de los vertebrados $\quad$.......... 39

I PARTE II. NEUROPÉPTIDOS

Capítulo 5. Neuropéptidos. Neurotransmisores.

Neuromoduladores. Neurohormonas ................... 51

Capítulo 6. Familias de neuropéptidos.

Filogenia y ontogenia de los neuropéptidos.

Distribución de los neuropéptidos .......................... 57

Capítulo 7. Biosíntesis y procesamiento de los neuropéptidos ...... 69

Capítulo 8. Liberación y receptores de los neuropéptidos ........... 77

Capítulo 9. Degradación enzimática de los neuropéptidos ............ 85

\ PARTE III. MÉTODOS UTILIZADOS PARA ESTUDIAR LOS NEUROPÉPTIDOS

Capítulo 10. Métodos utilizados para estudiar los neuropéptidos 
I PARTE IV. FUNCIONES EN LAS QUE INTERVIENEN

\section{LOS NEUROPÉPTIDOS}

Capítulo 11. Dolor. Analgesia. Acupuntura …......................... 109

Capítulo 12. Termorregulación …....................................... 117

Capítulo 13. Glucorregulación ........................................... 123

Capítulo 14. Ingesta de alimentos y de líquidos ..................... 127

Capítulo 15. Inmunorregulación ............................................. 139

I PARTE V. IMPLICACIONES CLÍNICAS DE LOS NEUROPÉPTIDOS

Capítulo 16. Asma .......................................................... 151

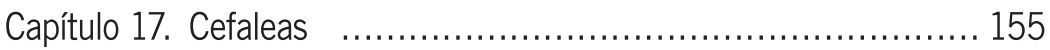

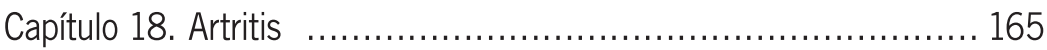

Capítulo 19. Envejecimiento ............................................ 169

Capítulo 20. Demencias. Enfermedad de Alzheimer ................. 175

Capítulo 21. Enfermedad de Parkinson .................................. 193

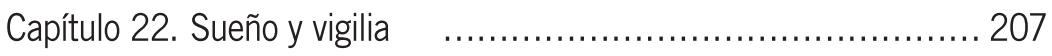

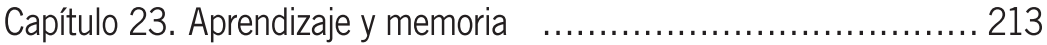

Capítulo 24. Alcoholismo …............................................ 221

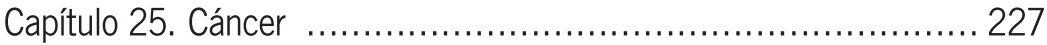

Capítulo 26. Esquizofrenia .............................................. 231

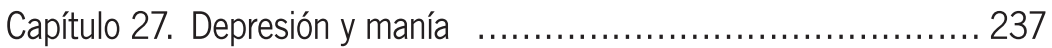

Capítulo 28. Suicidio ….................................................. 243

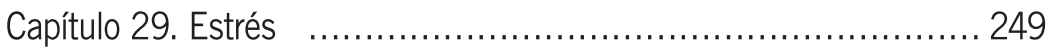

Capítulo 30. Epilepsia ................................................... 257

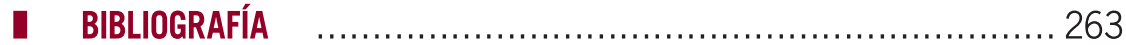




\section{Presentación}

Cuando me solicitaron hacer la presentación del libro: 'Avances en Neurociencias: Neuropéptidos. Investigación básica y clínica', de los doctores Rafael Coveñas, de la Universidad de Salamanca, y Luis Aguilar, de la Universidad Peruana de Ciencias Aplicadas (UPC), aceptécon gran satisfacción y curiosidad por adentrarme en uno de los temas más modernos de investigación en el campo de las neurociencias. Esperaba encontrar un libro denso y de difícil lectura dada la complejidad y la amplitud del tema. Por el contrario, me di con la grata sorpresa de encontrar un libro fácil de leer, muy ilustrado y que presenta en forma exhaustiva, pero a la vez didáctica, uno de los temas más avanzados y modernos en el campo de la organización y función del sistema nervioso y sus alteraciones patológicas. Por sus características, el libro es adecuado tanto para estudiantes de carreras en ciencias de la salud y ciencias biomédicas como para clínicos e investigadores en el campo de las neurociencias.

El libro está dividido en cinco partes, en la parte I se hace una revisión de la estructura microscópica del sistema nervioso, con énfasis en la importancia funcional de la neurona, la neuroglia y la sinapsis. Se tratan temas tan importantes como la regeneración y la muerte neuronales. A lo largo de los capítulos, se insertan recuadros en los que se señalan las relaciones entre la alteración de una estructura y determinadas enfermedades.

En la parte II, se presenta 'el estado del arte' sobre los neuropéptidos: qué son, cómo se sintetizan, cuáles son los diversos tipos que existen y cuáles son las funciones que cumplen tanto en el sistema nervioso como en otras partes del organismo. El tratamiento de los temas es exhaustivo y las ilustraciones son excelentes, lo que hace que sean de fácil comprensión.

La parte III trata sobre los métodos para estudiar los neuropéptidos. En esta parte, los autores demuestran toda su experiencia de investigación en este campo y nos presentan de manera muy clara las técnicas más actuales de estudio de estas pequeñas, pero importantísimas, moléculas.

En la parte IV, se presentan las funciones en que intervienen los neuropéptidos: el dolor, la analgesia, la acupuntura, la termorregulación, la ingesta de alimentos y de líquidos y la inmunorregulación. 
La parte V es la más extensa del libro, en ella se trata sobre la importancia clínica de los neuropéptidos en aspectos de la salud tan importantes en el siglo XXI como: el envejecimiento, el aprendizaje y la memoria, la enfermedad de Alzheimer, el alcoholismo, el cáncer, la depresión y la manía, el estrés y otras condiciones igualmente importantes. En cada uno de los temas, se revisan la fisiopatología y los mecanismos moleculares de la situación de salud, con énfasis en la importancia de los neuropéptidos, se relaciona la investigación básica y aplicada y se marcan derroteros para temas futuros de investigación.

La bibliografía es muy extensa y actualizada, lo que convierte al libro en una referencia obligada para investigadores y estudiosos del tema.

Felicito a los autores de este libro. Este esfuerzo de colaboración entre dos investigadores, uno peruano y el otro español, que remontando la distancia se organizan para escribir un texto de muy alta calidad, va a dar frutos muy destacados al poner al alcance de la comunidad científica de ambos continentes un tema de gran actualidad y trascendencia que de seguro despertará el interés por la investigación en el campo de los neuropéptidos.

\section{Dra. Graciela Risco de Domínguez}

Decana de la Facultad de Ciencias de la Salud Universidad Peruana de Ciencias Aplicadas (UPC) 


\section{Prólogo}

Hace ya muchos años, al menos para el autor de estas líneas, que unos pocos iluminados, no sin la oposición de otros tantos, decidimos iniciar unos cursos en neurociencias abiertos a alumnos y profesores latinoamericanos, primero en la sede de La Rábida -Huelva- de la Universidad Internacional de Andalucía y más tarde en la Universidad Pablo de Olavide de Sevilla, en esta última, bajo los auspicios de El Colegio de América. El presente libro es una muestra de que las distancias (físicas) son relativas y que lo que importa son las cercanías intelectual y emocional. Los autores de este libro han sido profesor-Rafael Coveñas, Salamanca, España-y alumno -Luis Aguilar, Lima, Perú- de los cursos arriba mencionados y demuestran que 11.000 kilómetros de distancia son salvables fácilmente, con afinidad y tesón.

Este libro trata sobre los neuropéptidos. Las sustancias neuroactivas, como por ejemplo los neuropéptidos, tienen en esta obra una presentación ordenada y en detalle, lo que permite saber su ubicación en el sistema nervioso, su participación en la fisiología cerebral y, por último, su relación con muy diversas enfermedades neurológicas.

Los autores presentan a estas características moléculas del sistema nervioso desde sus propiedades submoleculares hasta su intervención en procesos fisiológicos normales y patológicos. Los métodos científicos y experimentales utilizados en este largo estudio son explicados en forma detallada para que, en su caso, puedan ser replicados por profesionales de otros centros de investigación.

Las neurociencias tienen en el estudio de estas moléculas una forma de acercamiento al entendimiento del sistema nervioso y su investigación básica justifica las líneas de desarrollo posibles en la investigación clínica.

La amplia gama de publicaciones científicas relacionadas con los neuropéptidos se presenta y comenta a lo largo de 30 capítulos en un lenguaje preciso, aunque sencillo y claro a la vez, para que tanto el estudiante como el especialista puedan obtener el máximo provecho de su lectura.

Sirva este libro como consulta, pero también como fuente de futuras colaboraciones entre profesionales de diversas especialidades que se involucren en este tipo de estudios o 
investigaciones, especialmente de los países de habla hispana, y asíaportar al entendimiento de la función del sistema nervioso y su manifestación externa, el comportamiento como definición de la neurociencia.

Desde este breve prólogo quiero agradecer la aparición de esta obra en lengua española, por lo que supone de esfuerzo de elaboración, redacción y edición, y, en particular, felicito a los autores por haber llevado a cabo esta ingente tarea en un país que recién se abre a la inmensa tarea de entender nuestro cerebro, lo que es lo mismo que decir, entender lo que somos, lo que pensamos, lo que sentimos. Espero que este libro sirva de impulso editorial a otras muchas publicaciones relativas al enorme campo de las neurociencias.

Prof. José M. Delgado García

División de Neurociencias

Universidad Pablo de Olavide

Sevilla, España 


\section{Prefacio}

Las neurociencias realizan el estudio científico del sistema nervioso y su manifestación externa, el comportamiento.

Ha sido nuestra intención, al escribir este libro, transmitir y organizar muchos de los conocimientos generales y específicos que se disponen actualmente sobre los neuropéptidos (péptidos constituidos por menos de cien aminoácidos que son sintetizados por las células nerviosas); un campo de las neurociencias que se ha desarrollado considerablemente en los últimos años. Así, por ejemplo, al buscar la palabra 'neuropeptides' en PubMed aparecieron 270.196 artículos. El campo de las neurociencias se desarrollará aún más en el futuro, ya que generalmente los neuropéptidos se encuentran ampliamente distribuidos en el sistema nervioso central y periférico, así como están involucrados en un gran número de patologías. Actualmente, existe un número creciente de investigadores de diversas disciplinas (neuroanatomistas, neurohistólogos, neurofisiólogos, neuropatólogos, bioquímicos, inmunólogos ...) que se dedican al estudio de los neuropéptidos aplicando cada vez métodos más sofisticados.

El texto ha sido dividido en cinco grandes apartados: I. Introducción; II. Neuropéptidos; III. Métodos utilizados para estudiar los neuropéptidos; IV. Funciones en los que intervienen los neuropéptidos y V. Implicaciones clínicas de los neuropéptidos. En la parte I, se habla sobre las neuronas, la glía, la sinapsis y la organización general del sistema nervioso. En la parte II, se trata sobre el concepto de neuropéptido, las familias de neuropéptidos, la síntesis y liberación de los neuropéptidos, los receptores de los neuropéptidos y sobre la degradación enzimática de los neuropéptidos. En la parte III, se recoge los principales métodos que existen para conocer la distribución y función de los neuropéptidos en el sistema nervioso. La parte IV recoge algunas de las funciones (dolor, termorregulación, inmunorregulación...) en las que intervienen los neuropéptidosy por último en la parte Vse incluyen lasimplicaciones clínicas de los neuropéptidos en diversas patologías (asma, cefaleas, Alzheimer, Parkinson, esquizofrenia...).

En los cinco grandes apartados, mencionados anteriormente, se ha resaltado tanto la investigación básica como la aplicada realizada sobre los neuropéptidos y la interrelación que debe existir entre ambas. Por este motivo, hemos titulado al libro 'Avances en Neurociencias: 
Neuropéptidos. Investigación básica y clínica'. Ha sido uno de los objetivos marcados, a la hora de redactar el libro, plasmar que la investigación básica es fundamental para, en el futuro, aplicar los conocimientos básicos obtenidos, ya que los neuropéptidos están implicados en numerosas patologías. El texto ha recogido numerosas líneas de investigación que existen sobre los neuropéptidos, ya que consideramos que lo más importante no es lo que ya se conoce, sino resolver las numerosas e interesantes preguntas que se puede plantear actualmente sobre los neuropéptidos (preguntas que pueden surgir a partir de los datos presentados en el texto), que nos permita en el futuro conocer mejor la distribución de los neuropéptidos en el sistema nervioso central y periférico, así como las funciones en las que intervienen.

El texto va dirigido no solo a los especialistas en neurociencias, sino también a alumnos que cursan los últimos años de licenciatura (Biología, Medicina, Farmacia, Veterinaria, Bioquímica, Psicología...) y a aquellos alumnos que realizan estudios de tercer ciclo (o doctorado) y que quieran introducirse en el fascinante mundo de los neuropéptidos. Esperamos que este texto sea útil a los docentes y/o investigadores que enseñan e investigan el sistema nervioso. Deseamos que el texto sirva a los docentes, ya que presenta una recopilación ordenada de numerosos trabajos de investigación publicados en revistas/libros especializados sobre los neuropéptidos, así como a los investigadores en dicho campo, para que propongan nuevas hipótesis y líneas de investigación que ayuden en el futuro a comprender y conocer mejor la distribución y función de los neuropéptidos en el sistema nervioso.

Finalmente, queremos agradecer a los profesores Salvador González-Barón y José Ángel Narváez del Departamento de Fisiología y Farmacología de la Universidad de Málaga (España) el apoyo y los ánimos recibidos, antes y durante, la redacción del libro.

En resumen, nuestra intención ha sido recopilar en el texto, tanto investigaciones propias como ajenas sobre los neuropéptidos, así como la experiencia docente adquirida (ya que en la Universidad de Salamanca, desde el año 1996, se imparte una asignatura de libre elección sobre los neuropéptidos), que permita a los que utilicen el libro, abrir 'nuevas puertas' en el campo de las neurociencias y los neuropéptidos.

Rafael Coveñas-Rodríguez PhD.

Luis Ángel Aguilar-Mendoza PhD.

Durante la fase final de la redacción del manuscrito, se ha producido la muerte del doctor Pedro Yi, profesor de la facultad de Veterinaria y Zootecnia de la Universidad Peruana Cayetano Heredia y revisor del presente libro. Ha sido un duro golpe. Este libro está especialmente dedicado a él. Las cualidades humanas y científicas de Pedro eran excelentes. Todos hemos aprendido de él y todos podemos decir lo mejor que se puede decir de un ser humano: fue una buena persona. 
PARTE I

\section{INTRODUCCIÓN}




\section{Neuronas y glía}

\section{NEURONAS}

El cerebro humano es la estructura más compleja del organismo y en la que se expresan más genes, contiene aproximadamente cien mil millones de neuronas y billones de conexiones neuronales. La neurobiología es la disciplina que estudia el sistema nervioso, mientras que la neurología se encarga de estudiar las enfermedades del sistema nervioso.

\section{Morfología}

En las neuronas o células nerviosas se diferencian tres regiones:

\section{- Soma neuronal}

Contiene al núcleo. Es donde se encuentran los orgánulos (complejo de Golgi, retículo endoplásmico rugoso...) y la lipofuscina (pigmento que se corresponde con los residuos de la actividad enzimática de los lisosomas; su número aumenta con la edad). Contiene un solo centríolo (disposición de los microtúbulos: $9+0$ ).

\section{- Dendritas}

Casi todas las neuronas contienen dendritas que parten del soma neuronal. Sin embargo, las neuronas en 'T' de los ganglios de la raíz dorsal, se caracterizan por no poseer dendritas. Las dos prolongaciones que se originan a partir de la única prolongación que parte del soma neuronal se corresponden morfológicamente con 
axones, aunque la terminación periférica actúa funcionalmente como un receptor. En esta neurona la transmisión del impulso nervioso no pasa por el soma neuronal (Figura 1).

\section{Axón}

La mayoría de las neuronas contiene un axón que parte del soma neuronal. Sin embargo, hay neuronas que no tienen axón. Es el caso de las neuronas de la retina (extensión del sistema nervioso central) denominadas amacrinas y horizontales (Figura 1.1).

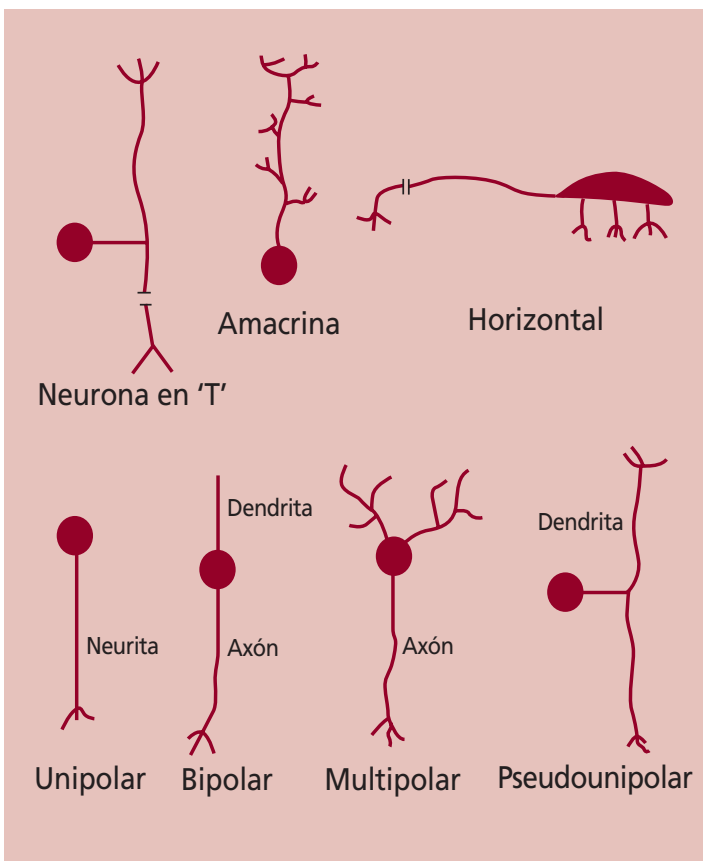

Figura 1.1 Neuronas sin dendritas (neuronas en ' $T$ '). Neuronas sin axón (amacrinas y horizontales). Clasificación de las neuronas por el número de prolongaciones (unipolar, pseudounipolar, bipolar, multipolar).

\section{NEURONASY ENFERMEDADES}

En muchas enfermedades del sistema nervioso central se han descrito los procesos de degeneración y muerte neuronales. Así, por ejemplo, ambos procesos se han observado en las siguientes enfermedades:

- Huntington: la muerte neuronal en los núcleos caudado y putamen produce movimientos involuntarios y demencia.

- Parkinson: al morir las neuronas dopaminérgicas de la sustancia negra aparecen los temblores típicos de esta enfermedad.

- Esclerosis lateral amiotrófica: la muerte de las motoneuronas alfa, que contienen acetilcolina e inervan a la musculatura esquelética (voluntaria), implica una gran debilidad muscular en las extremidades superiores e inferiores.

- Lesión cerebelosa: la muerte de las neuronas de Purkinje del cerebelo, que contienen GABA (ácido gamma-aminobutírico), produce temblores y fallos en los movimientos finos de la mano.

\section{Clasificación}

Las neuronas se pueden clasificar atendiendo a numerosos criterios. Así, según:

- El número de prolongaciones: unipolares, pseudounipolares, bipolares y multipolares (Figura 1).

- La longitud del axón: neuronas de proyección (relé: axón largo) o interneuronas (intrínsecas: axón corto).

- El tamaño del soma: gigantes, grandes, medianas y pequeñas. 
- La forma del soma: piramidales, esféricas, fusiformes, estrelladas...

- Las conexiones: al núcleo/núcleos del sistema nervioso a donde se proyectan.

- Lassustanciasneuroactivas(neuropéptidos...) que contienen.

\section{GLÍA}

La glía se denomina también neuroglia. Son células no nerviosas (no transmiten el impulso nervioso).

\section{Clasificación}

En el sistema nervioso central (SNC), la glía está constituida por las siguientes células (Figura 1.2):

- Astrocitos. Se clasifican en: protoplasmáticos, fibrosos, mixtos, de Bergmann y de Müller.

- Oligodendrocitos

- Microglia

- Ependimocitos

En el sistema nervioso periférico (SNP), la glía está constituida por las:

- Células satélites de los ganglios periféricos.

- Células de Schwann. Son atacadas por la bacteria Mycobacterium leprae, que origina la lepra (hanseniasis). La bacteria, tras unirse a receptores específicos que están en la membrana plasmática de la célula de Schwann, penetra en la célula glial y da inicio al proceso de desmielinización, que daña al axón. Además, mediante un conjunto de reacciones en cadena, aparece un proceso inflamatorio.

\section{Astrocitos}

Los astrocitos (Figura 2), en general, se caracterizan por presentar:

- Numerosos filamentos ricos en GFA (proteína ácida gliofibrilar).

- Grandes cantidades de glucógeno.

- Un tamaño grande.

- Uniones entre ellos: desmosomas y uniones en hendidura ( $g a p)$.

- Proteína ligante de calcio S-100.

- Un núcleo muy eucromático y un citoplasma muy electrotransparente cuando se observan con el microscopio electrónico.

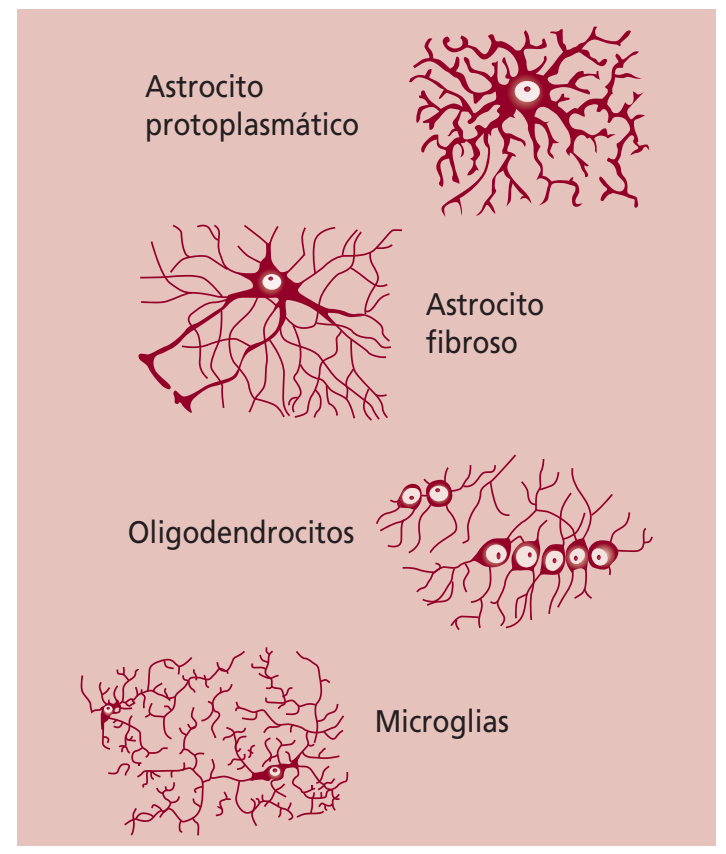

Figura 1.2. Morfología de los astrocitos protoplasmáticos y fibrosos, de los oligodendrocitos y de la microglia. 
【 Prolongaciones (pies) que rodean a los capilares sanguíneos y que forman parte de la barrera hematoencefálica.

- Los astrocitos protoplasmáticos se localizan fundamentalmente en la sustancia gris; los fibrosos, en la sustancia blanca y los mixtos, en la superficie del cerebro (forman la vaina glial externa; así, separan a las neuronas de las meninges). Los astrocitos de Bergmann se localizan en el cerebelo (corteza), mientras que los astrocitos de Müller se encuentran en la retina.

- Sus prolongaciones están alrededor de los somas neuronales (hay uniones en hendidura entre los astrocitos y las neuronas), de las dendritas y de las espinas dendríticas, de los axones (en el nodo), de las zonas sinápticas y de la zona basal de los ependimocitos.

- Los astrocitos originan astrocitomas (tumores, por lo general, malignos)

Se ha demostrado que los astrocitos intervienen en las siguientes funciones:

- Forman parte (mediante los pies) de la barrera hematoencefálica. En los vertebrados superiores, la barrera hematoencefálica está formada por las células endoteliales (con uniones ocludens o tight junction), los pericitos, las láminas basales de las células endoteliales y de los pericitos y por los astrocitos. Además, se sabe que en los vertebrados superiores los astrocitos son los responsables de inducir y mantener las uniones ocludens entre las células endoteliales. En los vertebrados inferiores (peces, anfibios), los astrocitos son los responsables directos de formar la barrera hematoencefálica.

- Tras una lesión, los astrocitos ocupan la zona lesionada y forman el tejido cicatrizal.

- Sintetizan proteínas de la matriz extracelular y moléculas de adhesión, como por ejemplo:

- N-CAM (nerve cell-nerve cell adhesion molecule)

- Laminina

- Fibronectina

- Citotactina

- Familia J-1: janusina y tenascina

La janusina y la tenascina, así como la laminina, la fibronectina y la citotactina, intervienen en la migración neuronal, la formación de las vías nerviosas y la formación de los agregados neuronales (núcleos del SNC).

- Sintetizan factores neurotróficos, como por ejemplo la interleucina-1 (IL-1), la proteasa nexina I (PNI, un inhibidor de proteasas) y el ADNF (activity-dependent neurotrophic factor).

- Intervienen en la detoxificación del SNC, pues captan metales, eliminan amonio...

- Captan potasio extracelular y, así, regulan la concentración extracelular de este ión. Cuando la concentración del ión potasio aumenta en el compartimento extracelular, los astrocitos lo incorporan a su citoplasma, a través de las uniones en hendidura que poseen. Es un proceso muy importante, ya que la transmisión del impulso nervioso a 
Si desea continuar leyendo, puede adquirir el libro en formato físico a través de nuestra tienda virtual.

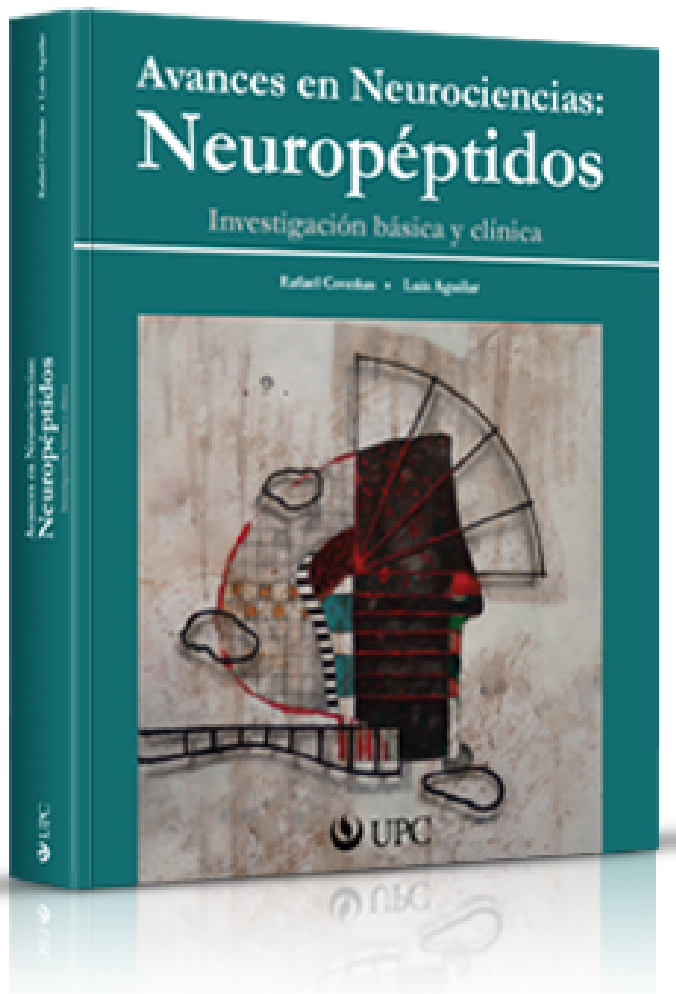

